\section{Dielectric Behaviour of Methyl Palmitate : Evidence of Resonance Absorption}

THe complex permittivity $x=x^{\prime}-j x^{\prime \prime}$ of methyl palmitate, $\mathrm{C}_{15} \mathrm{H}_{31} \mathrm{COO} . \mathrm{CH}_{3}$ (melting point (sharp) $29 \cdot 7^{\circ} \mathrm{C}$.), has been determined at room temperature $\left(17-20^{\circ} \mathrm{C}\right.$.) over the frequency-range $50-3 \times 10^{10}$ eycles/sec., with the results shown in the diagram, in which $x^{\prime \prime}$ is presented in terms of the tangent of the dielectric loss angle, $\tan \delta=x^{\prime \prime} / x^{\prime}$. The $50-10^{4} \mathrm{c} . / \mathrm{s}$. measurements were made on a schering bridge; the $10^{4}-10^{8} \mathrm{c} . / \mathrm{s}$. ones by a reactance variation resonance method $^{1}$, and the higher-frequency measurements by use of a number of eavity resonators ${ }^{2}$.

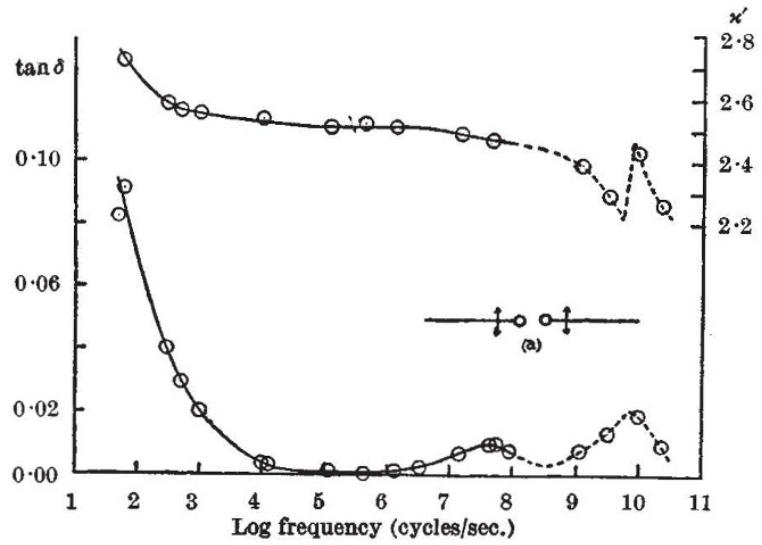

The results reveal three absorption regions in the spectrum investigated, and in seeking an explanation of the mechanism of these the following possibilities must be considered : normal (D.c.) conduction; anomalous conduction arising from the presence of aggregations of conducting impurity; dipole relaxation; and the occurrence in this frequency-range of a natural vibration frequency of the dipolar molecules or of parts of these molecules. The measured D.c. conductivity was found to account for no more than 1 per cent of the low-frequency value of $\tan \delta$, and the material tested was of such purity as to exclude the second possibility. In connexion with the third, if there exist two positions of equilibrium corresponding to opposite dipole directions with a transition probability of $p$ per sec., then energy absorption will occur around the frequency $p / 2 \pi \mathrm{c} . / \mathrm{s}$. With methyl palmitate there appear to be two such possibilities, involving rotation of the molecule about its axis and about an axis perpendicular to this. Since the probability of the latter type of rotation would seem to be small, the absorption between 50 and $10^{3} \mathrm{c} . / \mathrm{s}$. may perhaps be accounted for on this basis. Unfortunately, in the absence of measurements at still lower frequency, the peak of this absorption is undetermined; but there is reasonable correlation between the observed changes of $x^{\prime}$ and $\tan \delta$ in this region, and they indicate an effective resolved component of dipole moment of the order of 1.3 Debye units.

On this basis the second absorption is presum. ably due to a rotation of the molecule about its axis, though, since it has been concluded by Malkin ${ }^{3}$ from X-ray studies that methyl esters crystallize as double (end-on) molecules, the moving unit may be the double molecule. It can be estimated from the variation of $\tan \delta$ in the region of this second absorption that $x^{\prime}$ should decrease by $0 \cdot 06$, which is consistent with the observed variation of $x^{\prime}$, and suggests an effective resolved part of the dipole moment, in this case, of about 0.4 Debye units.

The variation of $x^{\prime}$ associated with the third, ultra high-frequency, absorption region would seem to identify this as a resonance phenomenon; although, if a curve be drawn through the four available experimental points, this variation appears as the inverse with respect to frequency of what is to be expected. This suggests that the four points at which measurements have thus far been made are inadequate to afford full resolution of the dispersion and absorption, and measurements at additional frequencies and at low temperatures are essential for clarification.

A resonance absorption in solids in the electrical spectrum has not previously been reported; but the prospect of this occurrence with compounds of the type under consideration within the $1 / 10$ to $1 / 100 \mathrm{~cm}$. wave-length band $\left(3 \times 10^{11}-3 \times 10^{12} \mathrm{c.} / \mathrm{s}.\right)$ has been predicted by Fröhlich ${ }^{4}$ The evidence that methyl esters crystallize in double molecules suggests, as one possibility, that the resonance may be due to oscillation of the component single molecules about an axis perpendicular to their length, in the manner indicated at $(a)$ in the diagram. If this be so, the frequency of vibration would presumably be lower than for the type of oscillation discussed by Fröhlich.

It is desired to emphasize the tentative nature of the explanations suggested above pending the com. pletion of further work now in progress.

Our thanks are due to Dr. L. Hartshorn, of the National Physical Laboratory, for help in connexion with the low-frequency measurements, and of one of us for a studentship provided by the Australian Council for Scientific and Industrial Research.

\section{J. S. DRYDEN \\ WIILIS JACKSON}

Electrical Engineering Department,

Imperial College of Science and Technology, London, S.W.7. Sept. 1.

${ }^{1}$ Hartshorn, L., and Ward, W. H., J. Inst. Elect. Eng., 79, 597 (1936). ' Horner, F., Taylor, T. A., Dunsmuir, R., Lamb, J., and Jackson, W., J. Inst. Elect. Eng., 93, Part III, 53 (1946).

s Malkin, J., J. Chem. Soc., Part II, 2796 (1931).

4 Fröhlich, H., E.R.A. Report, No. $L / T 157$.

\section{Velocity of Sound in Free Air}

A PREvious communication ${ }^{1}$ described an oscillographic method for measuring the velocity of sound in air. Further experiments have been made during the past four years, with the aid of a grant from the Research Committee of King's College, Newcastle. upon-Tyne, and during 1947 a series of $940 \mathrm{de}$ terminations was made in the Bute Hall of the University of Glasgow.

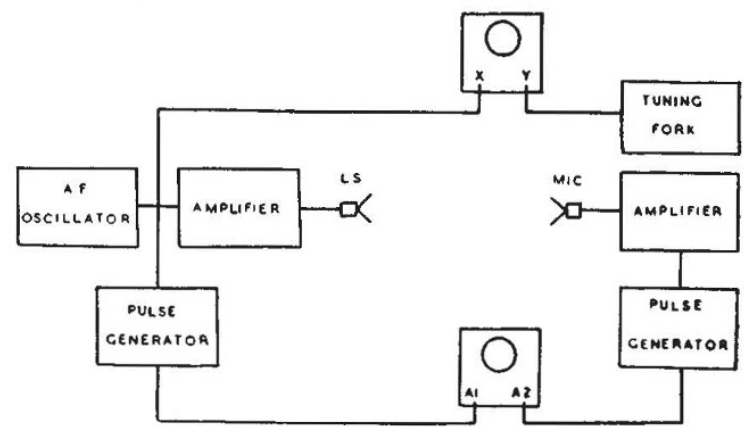

Fig. 1. General arrangement of apparatus 